Discussion Paper No. 05-66

\title{
Vocational Training and Gender: Wages and Occupational Mobility Among Young Workers
}

Bernd Fitzenberger and Astrid Kunze

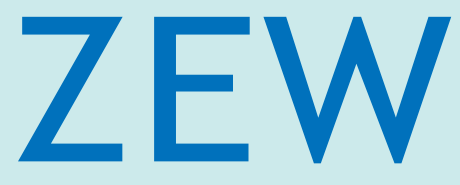

Zentrum für Europäische Wirtschaftsforschung $\mathrm{GmbH}$

Centre for European

Economic Research 
Discussion Paper No. 05-66

\section{Vocational Training and Gender: Wages and Occupational Mobility Among Young Workers}

Bernd Fitzenberger and Astrid Kunze

Download this ZEW Discussion Paper from our ftp server:

ftp://ftp.zew.de/pub/zew-docs/dp/dp0566.pdf

Die Discussion Papers dienen einer möglichst schnellen Verbreitung von neueren Forschungsarbeiten des ZEW. Die Beiträge liegen in alleiniger Verantwortung der Autoren und stellen nicht notwendigerweise die Meinung des ZEW dar.

Discussion Papers are intended to make results of ZEW research promptly available to other economists in order to encourage discussion and suggestions for revisions. The authors are solely responsible for the contents which do not necessarily represent the opinion of the ZEW. 


\section{Non-technical Summary}

It is a general empirical finding that a considerable part of the gender wage gap is related to the segregation of men and women in different occupations (see e.g. Dolado et al., 2003, for evidence on Europe). Furthermore, if segregation exists from the beginning of working careers and persists, this can be interpreted as a lock-in effect for women in low wage occupations (see Kunze, 2005). The question arises whether mobility, given segregation at an early stage during careers, is an important factor which reduces gender differences.

This paper investigates the relationship between the gender wage gap, the choice of training occupation, and occupational mobility. Our empirical analysis uses a West-German sample of young workers with apprenticeship training covering the time period 1975-2001. The longitudinal data allow us to observe wage and working careers for young workers from the beginning of careers. Typical for the apprenticeship training system is that workers make occupational career choices early during their careers and that women and men pursue very different occupational careers. Therefore, the particular advantage of focusing on this group of workers is that the systematic occupational segregation through apprenticeship training allows us to disentangle mobility effects during the early career from segregation.

We reconsider whether women are locked in low wage careers through occupational segregation (Kunze, 2005) and whether they can move up to higher wage paths through occupational mobility. We furthermore investigate whether patterns have changed across cohorts during the period 1975 and 2001 and whether effects vary across the wage distribution. The main results are: First, while there exists a persistent gender wage gap over experience, the gap has decreased over time. Second, in the lower part of the wage distribution, the gap is highest and it increases with experience. Third, occupational mobility is lower for women than for men and the wage gains due to occupational mobility are higher for men than for women, especially in the lower part of the wage distribution. We conclude that occupational mobility has helped to reduce the gender wage gap, but lock-in effects are still stronger for women compared to men. 


\title{
Vocational Training and Gender: Wages and Occupational Mobility among young Workers*
}

\author{
Bernd Fitzenberger ${ }^{\dagger}$ and Astrid Kunze ${ }^{\ddagger}$
}

August 2005

\begin{abstract}
This paper investigates the relationship between the gender wage gap, the choice of training occupation, and occupational mobility. We use longitudinal data for young workers with apprenticeship training in West Germany. Workers make occupational career choices early during their careers and women and men pursue very different occupational careers. We reconsider whether through occupational segregation women are locked in low wage careers (Kunze, 2005) or whether they can move up to higher wage paths through mobility. We furthermore investigate whether patterns have changed across cohorts during the period 1975 and 2001 and whether effects vary across the distribution. The main results are: First, while there exists a persistent gender wage gap over experience, the gap has decreased over time. Second, in the lower part of the wage distribution, the gap is highest and it increases with experience. Third, occupational mobility is lower for women than for men and the wage gains due to occupational mobility are higher for men than for women, especially in the lower part of the wage distribution. We conclude that occupational mobility has reduced the gender wage gap, but lock-in effects are still stronger for women compared to men.
\end{abstract}

Keywords: gender wage gap, actual experience, occupational mobility, apprenticeship

JEL: C21, J16, J24, J31, J62, J7

*This paper is forthcoming in the Oxford Review of Economic Policy. We are grateful for very helpful comments by two anonymous referees and by the editor Christian Dustmann which resulted in a significant improvement of the paper. We thank Karsten Kohn for excellent research assistance. All errors are our sole responsibility.

${ }^{\dagger}$ Corresponding author: Goethe University Frankfurt, ZEW, IZA, IFS. Address: Faculty of Business and Economics, Goethe-University, PO Box 111932 (PF 247), 60054 Frankfurt am Main, Germany. E-mail: fitzenberger@wiwi.uni-frankfurt.de

$\ddagger$ NHH, IZA. Address: Norwegian School of Economics and Business Administration, Helleveien 30, N- 5045 Bergen, Norway. E-mail: astrid.kunze@nhh.no 


\section{Introduction}

It is a general empirical finding that a considerable part of the gender wage gap is related to the segregation of men and women in different occupations. ${ }^{1}$ If segregation exists from the beginning of working careers and persists, this can further be interpreted as a lock-in effect for women in low wage occupations. ${ }^{2}$ The question arises whether mobility, given segregation at an early stage during careers, is an important factor which reduces gender differences. Since occupational mobility is likely to be a form of career progression (Fitzenberger and Spitz, 2004), social attitudes regarding gender roles could be an important reason for stronger lock-in effects experienced by women compared to men. Based on international survey data, Fortin (2005) emphasises the importance of social attitudes for differences in labor market outcomes of females.

This paper investigates the relationship between the gender wage gap, the choice of occupation, and occupational mobility. Our empirical analysis uses a West-German sample of young workers with apprenticeship training covering the period 1975-2001. In the following, we refer to those workers with apprenticeship as skilled, excluding unskilled and those with technical college or university degrees. Typically, an apprenticeship is started after 9 or 10 years of schooling. While in training, apprentices have an apprenticeship employment contract. Training takes 2.5-3.5 years depending on the training scheme (occupation). Firms have to follow national training curricula and apprentices attend vocational schools during one to two days a week. The apprenticeship is completed with a certificate after successful completion of a regionally unified oral, written, and practical exam. Exams are taken at the chamber of the industry of the firm, as well as internally (for more details see Münch, 1992). Apprentices receive a relatively low wage which amounts to 20-30 percent of the wage of a skilled worker.

The advantage of focusing on this group of skilled workers is that the systematic occupational segregation through apprenticeship training allows us to disen-

\footnotetext{
${ }^{1}$ For evidence on European countries see (Dolado et al., 2003).

${ }^{2}$ It has also been shown for German workers qualified through apprenticeship training that early segregation has persistent effects on the gender wage gap across experience levels (Kunze, 2005).
} 
tangle mobility effects during the early career from segregation. Other systems of work based training, where mobility reflects partly accumulation of human capital until full qualification as a skilled worker, make it more difficult to study these effects separately. Regarding the gender wage gap, it has been shown that it may also lead to high gender segregation and large gender wage gaps that exist from entry into the first job and remain high throughout the early career (Kunze, 2005). Hence, it looks as if women are locked into occupational careers. These results stem from averages across apprentices during the 1975-1990 period. In this study, we extend this analysis by investigating whether we find the same effects for different training cohorts during the longer period 1978-2001. Instead of focusing on averages, we also take the entire distribution of wages into account. ${ }^{3}$ Finally, we take occupational mobility into account.

Our main results are: First, while there exists a persistent gender wage gap over experience, the gap has decreased over time. Second, in the lower part of the wage distribution, the gap is highest and it increases with experience. Third, occupational mobility is lower for women than for men and the wage gains due to occupational mobility are higher for men than for women, especially in the lower part of the wage distribution. We conclude that occupational mobility has helped to reduce the gender wage gap, but lock-in effects are still stronger for women compared to men.

The remainder of the paper is organised as follows: In section 2, we review the economic background. In section 3, we describe the data and summary statistics. In section 4 , the results are presented. Section 5 concludes. The appendix discusses methodological aspects of the estimation approach and comprises tables with information on the data and estimation results.

\section{Economic Background}

This section provides a short review of the literature on (a) the gender wage gap and the choice of occupation/occupational segregation and (b) the gender wage

\footnotetext{
${ }^{3}$ Fitzenberger and Wunderlich (2002) found that the gender wage gap by age for the group of skilled workers decreased between 1975 and 1995 and the reduction in the gap was strongest in the lower part of the wage distribution.
} 
gap and occupational mobility. We discuss how our subsequent empirical analysis is guided by the arguments put forward in the literature.

A natural starting point for discussing occupational segregation are self-selection models (Polachek, 1981). These models are based on human capital theory. They assume that atrophy rates of human capital are occupation specific and that women have better options outside of the labour market. Therefore, women have more interruptions in their labour market careers and are less willing to bear the costs of specific investment into their human capital. This rationalizes gender differences in occupational choice. Experience profiles in wages should be steeper for males compared to females, but the starting wages of females should be higher right after finishing apprenticeship. Self-selection models are not consistent with empirical findings showing that men earn more from entry into their first employment (Light and Ureta, 1995; Loprest, 1992; Kunze, 2005) and that the uncertainty about the turnover risk from the employers' perspective is the same for both genders (Light and Ureta, 1992). Our empirical analysis partly reexamines these points, thereby confirming the earlier results.

A positive gap between male and female starting wages can be rationalized if women are less attached to the labor market and show higher turnover rates. Therefore, men are selected by firms into occupations and jobs with higher specific training and higher wage growth even accounting for job or occupation changes (Barron et al., 1993; Kuhn, 1993; Royalty, 1996; Altonji and Blank, 1999, section 6.2.2). These arguments imply occupational segregation, a positive gender wage gap at entry, and a widening gap with tenure. Our empirical analysis analyses the entry wage gap and the evolution of the gender wage gap by actual experience. Regarding the turnover risk, we investigate occupational mobility and time spent in non-employment during the early career phase. We focus on experience rather than on tenure for the following reasons. First, tenure effects are also reflected in experience effects. Second, a large number of training firms train a larger number of apprentices than needed later as young workers. Thus, there is a lot of firm mobility after the end of the apprenticeship with firms trying to keep the better apprentices. Since some workers will realize the gains from their apprenticeship in other firms, it is crucial to investigate all former apprentices. Third, as a related point, job-to-job mobility is fairly high among young workers (Topel and 
Ward, 1992). Thus, focussing on tenure at the training firm, we would be likely to ignore an important part of the effects of the choice of training occupation and we would have to deal with a difficult selection issue.

Empirical studies have shown that occupational segregation is related to the gender wage gap (see e.g. Dolado, 2001, 2003, and Miller, 1987) as well as differences in schooling content (see e.g. Brown and Corocoran, 1997, and Paglin and Rufolo, 1990). In recent studies based on data for apprentices in Germany during the time period 1975 to 1990, Kunze (2003, 2005) finds that occupational segregation explains a large and persistent part of the gender wage gap during the early career. Gender wage differences are large from the beginning and virtually constant conditional on occupational segregation. While results are in contrast to predictions from self-selection models, they are consistent with models considering employer induced sorting mechanisms and firm specific training (Kuhn, 1993; Barron et al., 1993). Our empirical analysis investigates whether women are locked into low wage careers through apprenticeship training schemes. Similar to Kunze (2005), but based on a longer data set and distinguishing between different training cohorts, we analyse to what extent gender segregation in occupation explains the gender wage gap.

It has been shown that mobility is a driving factor of wage growth among young male workers in the U.S.. Topel and Ward (1992) find that young male workers experience approximately one third of early career wage growth through moving jobs. In a recent study for Finland, Kangasniemi (2004) finds that occupational mobility is much lower for female workers compared to male workers and that occupational mobility is mostly associated with promotions. Having a different focus, the study does not explicitly estimate the relationship between occupational mobility and the gender wage gap. Our subsequent empirical analysis investigates to what extent mobility counteracts the lock-in effect through early segregation or, put differently, whether the gender gap in occupational mobility is crucial for the persistence of the gender wage gap.

Fitzenberger and Spitz (2004) explicitly analyse the decision to change the occupation of work in a two period model. ${ }^{4}$ The model assumes that a change

\footnotetext{
${ }^{4}$ Occupational mobility in Germany is also analysed by Euwals and Winkelmann (2002), Fahr (2004), and Werwatz (2002). These studies do not look at gender differences.
} 
in occupation between period 1 and 2 takes only place if the random wage increase in the new occupation in the second period outweighs the loss in specific human capital accumulated in the training occupation. Workers differ by their unobserved, innate ability which both affect the return to training and the return to occupational change. Some implications of the model are analysed empirically for male workers in Germany. By comparing movers (workers who have changed their occupation) with stayers (workers who have not changed their occupation) both for the training occupation and the occupation of work, the authors find that occupational mobility results in a wage increase. Our empirical analysis reexamines for a much larger database whether occupational mobility is associated with moving to better paid occupations as part of career progression. If this is the case, lower occupational mobility among females causes a lock-in effect resulting in a persistent gender wage gap. Our empirical analysis also investigates to what extent the gender wage gap would be reduced if females exhibited male patterns in occupational choice and occupational mobility.

\section{Data and Summary Statistics}

We extract a sample of skilled workers from the newly released IAB employment subsample $(\mathrm{IABS})^{5}$ for the period 1975 to 2001 . The IABS is a 1 percent random sample drawn from the event history data file of the social security insurance scheme, the employment statistics, collected by the German Federal Bureau of Labour. It contains all dependent employees in the private sector, i.e. about 80 percent of total employment in Germany. Not included are: civil servants, selfemployed, unpaid family workers and people who are not eligible for benefits from the social security system. ${ }^{6}$ The IABS contains approximately 200000 individuals in every cross-section.

The large longitudinal sample and the long observation window allow us to measure education and employment histories for each worker from the same point in the career that is from age 15. Hence, we observe complete education and work histories up to the current employment spell. Particularly, we observe skill

\footnotetext{
${ }^{5}$ IABS in abbreviation for the Institut für Arbeitsmarkt und Berufsforschung Sample.

${ }^{6}$ For more details based on an earlier release of the data set, see Bender et al. (2000).
} 
accumulation while in apprenticeship giving us information about the training occupation, duration of training and other initial conditions. Furthermore, we can measure wage and work histories from entry into first employment onwards. Work histories are precisely measured by use of information on whether the employee is working or not, as reported in the data. ${ }^{7}$

The main variables for our analysis are the wage variable, work experience, the training occupation (apprenticeship) as well as the occupation of work. The wage variable we use in the empirical analysis is the wage in an employment spell after training and is defined as the logarithm of daily gross wages deflated by a standard CPI index for Germany. The reference year is 1995. We focus on fulltime workers and, hence, exclude observations with hours of work lower than 35. Although hours of work generally are an important explanatory factor of gender wage gap, focusing on full time workers eliminates differences in average hours, as Kunze (2005) has found for a similar sample of young skilled workers from the GSOEP 1984-1997. Hence, we do not need to control for hours of work. Work experience is precisely estimated from the rich information in the event history data set. ${ }^{8}$ Work experience is calculated by accumulating days of full time work for each individual. We transform it into years of work experience. Since we

\footnotetext{
${ }^{7}$ We identify skilled workers through our constructed variable measuring the duration of training with a firm, as well as the qualification status reported in the IABS after training. The original sample includes all workers who have only one consecutive period of training longer than 450 days. Hence, those who take more than one apprenticeship are excluded and therefore we do not need to deal with selection into further training. We also exclude workers who have earned a degree after or before training, such as in technical college or university. Workers must be employed as a skilled worker at least once after training. Furthermore, to capture the main group of skilled workers who have gone through typical training, we drop workers who are reported with training duration longer than 6 years, and who have started their career after training relatively late, that is later than age 25 . The average age at entry is approximately 20.5, see Kunze (2005). Finally, we restrict the sample to those who do not delay entrance into first employment by more than 2 years. 2 years is the maximum gap that would appear if national service applies. In Germany, national service is only compulsory for men and its length varies throughout the period between 12 and 18 months.

${ }^{8}$ Individual records in the IABS are organised in spells with the calendar date of start and end which are not longer than one year. A spell is reported for every change related to the employment and non-employment status. From the calendar dates and information on employment status, we generate the variable actual experience.
} 
follow workers through vocational training and work, we can observe the training occupation that we measure in the last spell of training, and the occupation of work afterwards. The latter may change across time for an individual reflecting career changes or promotion. Both occupational variables are measured by the same 2-digit codes. ${ }^{9}$ We measure (occupational) mobility by the first transition out of the occupation corresponding to the 2-digit training occupation.

$<$ Table 1 about here $>$

In order to compare results across training cohorts, we construct an indicator variable defined as the year of completing apprenticeship training. ${ }^{10}$ We construct three cohorts capturing the developments around the apprenticeship system from the late 1980s to the mid 1990s. We select the following three: 1978-1980, 198486, and 1990-93. Pooling some of them ensures a sufficiently large sample size to undertake detailed analysis within occupation groups. The final apprenticeship cohort we use stops training in 1993. This ensures that we follow almost all of them for at least 5 years of their work history after training.

In table 2 we list the number of observations in our final analysis sample split by sex and years of work experience (integer values). We cut off records after 10 years of work experience for the two earlier cohorts and after 5 years for the latest cohort. This is to ensure sufficient numbers of observations to do a statistical analysis within occupation groups. Furthermore, this is sufficient to observe mobility following apprenticeship training during the early career.

$<$ Table 2 about here $>$

In tables 3 and 4 , we list summary statistics measured at the first job for our final sample. The main route is to enter apprenticeship after 9 to 10 years of schooling. Noteworthy, the level of schooling prior to apprenticeship training

\footnotetext{
${ }^{9}$ The orginal occupation variable occorg (variable 'BERUF') with 130 different outcomes in the IABS is translated into a two-digit, occ2d (with 66 different outcomes), occupation variable, see table 1 . The original variable occorg is a consolidated version of 3 -digit occupation codes due to data protection reasons. Because of this limited information, we had to consolidate a number of categories when constructing our 2-digit variable which is coarser than the usual 2 -digit classification.

${ }^{10}$ Technically, it is the last year when the worker is reported to be in training.
} 
increased slightly across cohorts and, within the cohort completing training in 1990-1993, 9 percent of men and 5 percent of women have the Abitur degree, that takes usually 13 years. The duration of training increased over time from 2.51 years for the cohort in the late 1970s to 2.7 years for the cohort in the mid 1990s. Accordingly, the age at entry into the first job increased as well. This development captures an increase in quality of training and increase in preapprenticeship education. As a final summary statistic, we present the fraction of those who stay in the same occupation after apprenticeship. This we measure by comparison of the training occupation and the occupation of work in the first job. For both we use the original occupation code occorg as reported in the data source. Both for men and women the probability to stay was extremely high, 76-77 percent. While across cohorts this probability stayed almost constant for women, it decreased for men by 10 percentage points (ppoints). In the following, we denote the probability to move as mobility and we investigate differences between men and women.

$<$ Tables 3 and 4 about here $>$

\section{The Gender Wage Gap}

To describe the gender wage gap, we present means conditioning on experience. Since our sample of apprentices can be followed from the beginning of their working careers we can observe the entry wage and follow them over time without gap unless they stop working in a job subject to social security taxation, become self-employed or a civil servant. Experience-wage profiles are presented by sex and cohort group in Figure 1. Consistent with human capital theory, both for men and women, we find concavely shaped profiles that first increase more steeply and then increase at a decreasing rate. In line with previous findings, the figure shows already at entry a large gender wage gap which persists throughout the early career. This becomes even more clear from plotting the wage gap at the different levels of work experience. 
Figure 1: Wage profiles, by sex and apprenticeship graduation cohort
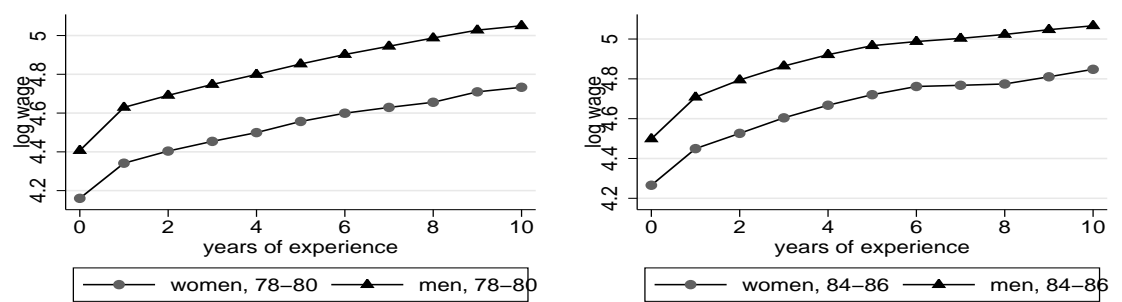

$\longrightarrow$ women, 84-86 — men, 84-86

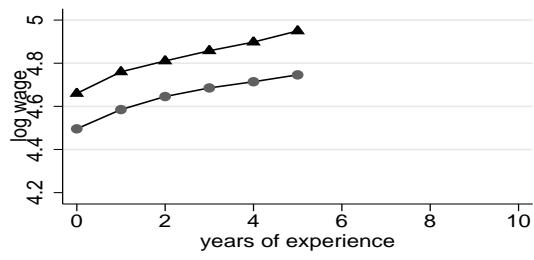

$\longrightarrow$ women, 90-93 $\longleftarrow$ men, 90-9ק

Figure 2 shows the mean gender wage gap for each cohort group separately which reveals interesting developments. First, the gender wage gap declined considerably over time from approximately 25 percent at entry wages to approximately 17 percent. Most of the drop occurs between the mid 1980s cohort group and the mid 1990s cohort group. It is difficult to say what the reason is. From our descriptives, it is not obvious that the improvement in the quality of training can explain this. In the following, we investigate further whether changes in occupational segregation and mobility can explain these patterns. ${ }^{11}$ Both for the cohort in the late 1970s and the mid 1990s, the gender wage gap increases by around 5 ppoints within 5 years of work, and for the earlier cohort by 10 ppoints within 10 years of experience. In contrast, the cohort entering the labour market between 1986-88 experienced a slight decline in the gender wage gap comparing the gap at zero and 10 years of experience.

\footnotetext{
${ }^{11}$ Other hypotheses could be that huge demand shocks around unification have had an impact, or that social attitudes have changed as pointed out by Fortin (2005) in this issue. We will not explore these two hypotheses further in the following.
} 


\section{Figure 2: Mean wage gap, by apprenticeship graduation cohort}

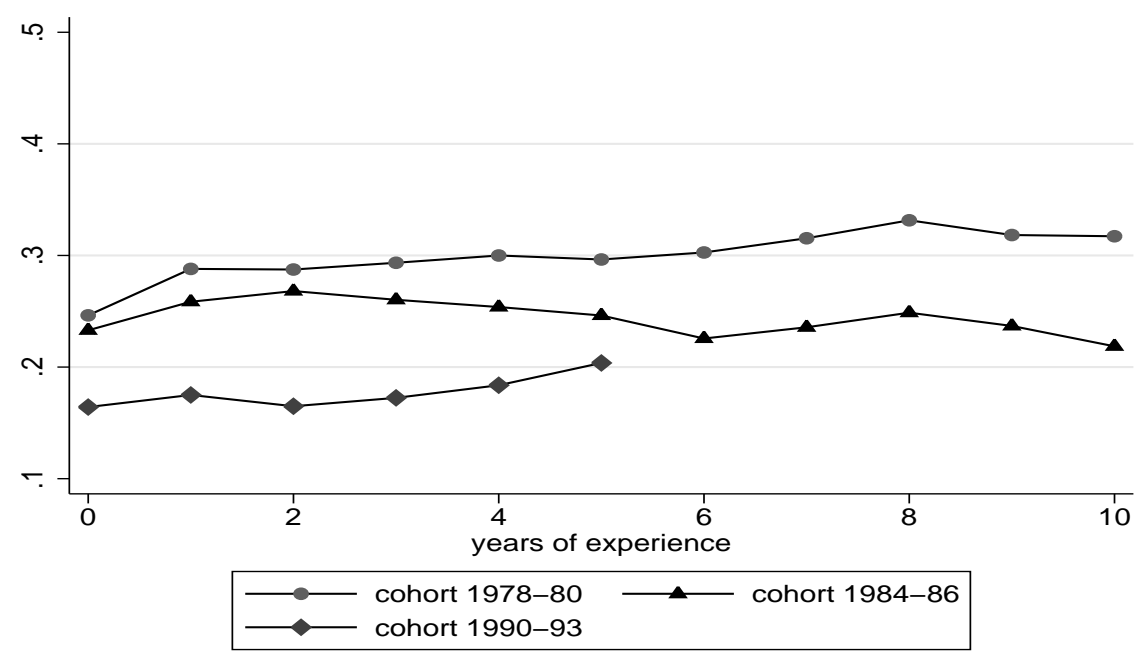

Second, looking in more detail at the gender wage gap across the entire distribution it appears that most action has taken place at the lower part of the distribution. This is shown in figure 3, where we present wage gaps at the 20th percentile, the median and the 80th percentile of the wage distribution. Most striking is that the gender wage gap is highest in the lower part and lowest in the upper part of the distribution. This holds for all cohorts. Hence, among skilled workers we do not observe that women get promoted only up to a certain level which is why then the gap widens at the upper end of the distribution. ${ }^{12}$ For the cohort in the late 1970s, the gap at the 20th percentile shows the largest increase from 20 percent at zero years of experience to 40 percent at 10 years. For the same cohort, the wage gap remained constant in experience looking at the median and 80th percentile. For the other cohorts, we find all throughout the distribution constant or slightly decreasing gender wage gaps in experience. Hence, the descriptive evidence suggests that, if lock-in effects are at work, they tend to work more strongly at the bottom of the distribution. Women at the lower end of the wage distribution may be less mobile or they may gain less from mobility compared to males.

\footnotetext{
${ }^{12}$ To test for glass ceiling effects, noteworthy, we would have to include women with a university degree in our sample (Albrecht, et al., 2003)
} 
Figure 3: Wage gap at 20th, 50th and 80th percentile, by cohort

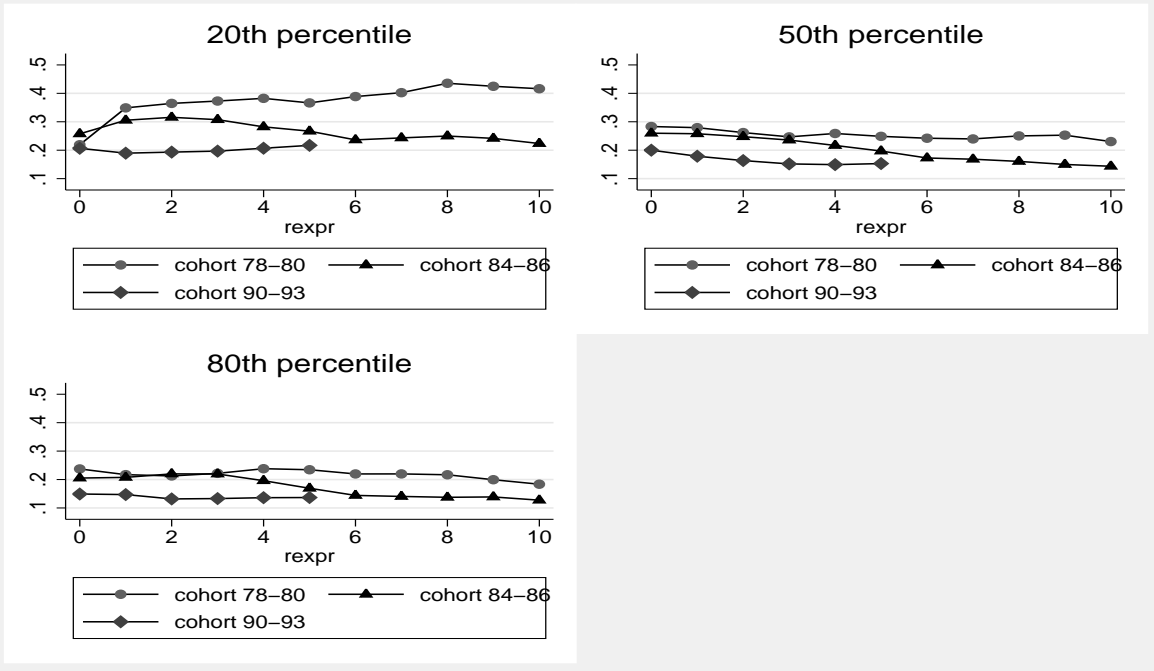

\section{Econometric Analysis}

The descriptive analysis so far has shown two main stylized facts on the gender wage gap among skilled workers: First, the gender gap in entry wages fell across cohorts from the mid 1970s to the mid 1990s. Second, the gap is largest at the lower end of the wage distribution. The following econometric analysis in sections 4.1 and 4.2 investigates the role of occupational segregation and occupational mobility in explaining these facts. Since the empirical analysis is mainly descriptive, we also assess in section 4.3 various potential selection issues.

\subsection{Occupational segregation and gender wage gap}

Skilled men and women are trained and work in quite different occupations. In addition, despite the fact that training schemes are offered in more than 300 occupations, more than 50 percent of both men and women are found in only four most popular training occupations. These are for men mechanical assemblers, technical occupations in electronics, occupations related to construction and woodworking, and sales occupations. For women, the most popular are sales occupations, business, finance and administrative occupations, occupations in the health sector and other service occupations. With the exception of sales assistance in popular occupations among men, fractions of women are very low and 
vice versa. Considering all occupations, we will as well see that mobility is low and hence occupational segregation is a persistent feature of the skilled labour market. Occupational segregation did not change across the three cohorts considered here in a way that this could explain the observed changes in the gender wage gap. Also the femaleness of an occupation (we define this as the difference between the share among females and among males choosing a specific occupation) did not change considerably during the period of observation (detailed results are available upon request). At the same time, one can show that relative to the overall gender wage gap women in the lower part of the distribution benefit from being in a female dominated occupation while women in the upper part benefit from being in a male dominated occupation.

\subsection{Occupational mobility and gender wage gap}

\subsubsection{Patterns of occupational mobility}

To describe to what extent workers are still working in the same occupation they have been trained in, figure 4 shows the fraction of stayers following workers over the early career. We include all training occupations and measure them at the 2-digit level. Overall mobility seems quite low, and it is lower for women than for men. Both for men and women stability has particularly increased for training cohorts in the 1990s, this is conditional on experience. At entry in all cohorts more than 80 percent of women work in the training occupation and approximately 72 percent of men. For the cohorts in the late 1970s and mid 1980s, after 5 years of work this fraction of stayers has declined to 60 percent of women and 50 percent of men. A further decline to 50 for women and 40 percent for men occurs after 10 years. For the 1990-93 cohort the decline is less pronounced. 


\section{Figure 4: Training to work transition - Fraction of stayers in the training occupation measured at the 2 digit level}

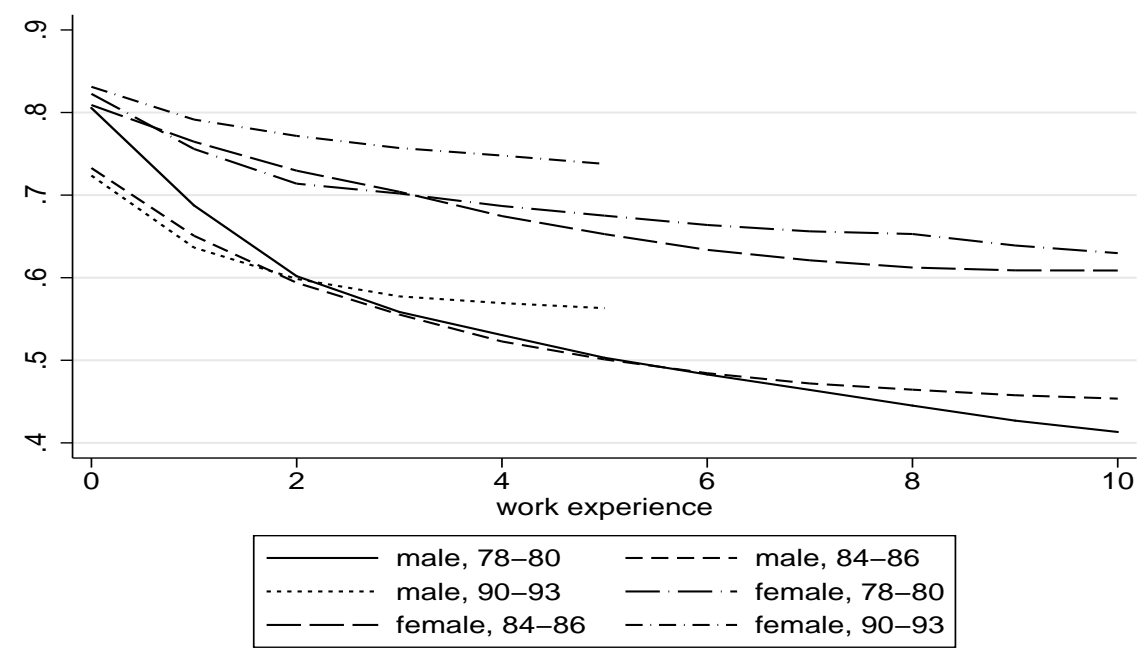

Following the discussion in section 2, occupational mobility is likely to be a key aspect of career progression since workers change occupation as a transition to a better paying job either with or without a change of the employer. Table 5 provides further evidence on gender differences in occupational mobility at the 2-digit level during the first ten years of work experience. We define dummy variables $D E X P_{k}$ for (integer) work experience at the beginning of employment spells lying in the intervals $k=0,1-3,4-5 / 4-6$, and $7-9$ years. ${ }^{13}$ We report the coefficients on these experience variables interacted with a dummy for male workers and, for specification 3, also for the gender dummy variables interacted with the average entry wage in the training occupation and with the difference between the individual entry wage and the average entry wage in the training occupation. $^{14}$

\footnotetext{
${ }^{13}$ Here and in the following, we use integer years of experience, i.e. the largest integer which is less than or equal to actual experience in years at the beginning of the employment spell and we restrict the analysis to the first ten years of work experience. $k=0$ represents those wage observations, for which $0 \leq$ actual experience $<1$. Analogously, $k=7-9$ represents $7 \leq$ actual experience $<10$.

${ }^{14}$ Here and in the following, the interaction terms between gender and all other covariates are normalized such that the experience specific gender gap is the estimated average gender difference holding all other covariates constant, see section on methodological aspects in the appendix.
} 
$<$ Table 5 about here $>$

The results in table 5 show that the gender gap in occupational mobility increases strongly with experience for the first cohort (specification 1). For the later cohorts, the gender gap is higher at low experience levels but the increase with experience is very small. Comparing males and females in the same training occupations (specification 2), the gender gap in mobility is reduced and the reduction is stronger for the later cohorts. Thus, there is some evidence that women are locked in training occupations with lower occupational mobility and this effect seems to have become more important for the later cohorts. However, one has to be careful not to relate this effect to the level of entry wages by training occupations. We find (specification 3), that the higher the average entry wage level the lower the mobility (except for male workers among the last cohort) and the individual wage position at entry is positively related to mobility. Though mostly significant, the wage variables have no impact on the estimated gender gap in experience since the latter remains at the same level as in specification 1. Apparently, occupational mobility does not overcome the strong segregation in training occupations. For the later cohorts, the gender gap in mobility is mostly related to the training occupations but this is not necessarily related to the entry wages. Given the persistence of segregation in training occupations, this finding by itself does not provide an explanation for the decline in the gender wage gap across cohorts. However, we can conclude that, within training occupations, female and male mobility patterns have converged for the later cohorts.

\subsubsection{Gender wage gap and occupational mobility}

Now, we investigate to what extent the gender wage gap is associated with the choice of training occupation and gender differences in occupational mobility. Table 6 provides estimates of the gender wage gap by experience intervals ( $D E X P_{k}$ for $k=0,1-3,4-5 / 4-6$, and $7-9$ years) controlling for a number of characteristics at entry. For each training cohort, one set of results also controls for the 2-digit training occupation and gender specific dummy variables for occupational mobility. We add both a dummy variable (pre move) for the fact that an individual later experiences an occupational change during the first ten years 
of work experience and a dummy variable (move effect) which is one after an occupational change occured. The difference between the move and pre move coefficient provides a conditional difference-in-differences (DID) estimate of the wage effect of mobility. We allow for dynamic effects of these dummy variables by interacting them with dummy variables for the experience level $\left(D E X P M_{k}\right.$ for $k=0,1-3,4-5 / 4-6$, and $7-9$ years) when occupational mobility occurred. We obtain both OLS and quantile regression results for the three quantiles $20 \%$, $50 \%$, and $80 \%$.

$$
<\text { Table } 6 \text { about here }>
$$

For the training cohorts $78-80$ and $84-86$, the gender wage gap increases strongly between the first and the second year of experience for the mean and the lower part of the distribution. With increasing experience, these gap measures remain fairly constant for the first cohort and decline strongly for the second cohort. In comparison, the gender wage gap is fairly constant at the median and at the $80 \%$-quantile for the first cohort and it decreases with experience for the later cohorts. For the 90-93 cohort, the gender wage gap declines at the mean and at all quantiles with experience. Without controlling for occupational variables the gender wage gap is generally higher in the lower part of the distribution and it becomes smaller for later cohorts. Controlling for occupational variables, the gender wage gap decreases strongly, except for the upper part of the wage distribution. We find almost no reduction for the two earlier cohorts at the $80 \%^{-}$ quantile. However, it is not possible to relate the quantile regression results to the previous estimates in the sense of attributing the changes in the gender wage gap to these additional controls. ${ }^{15}$ For this purpose, we reestimate the gender wage gap using the simulation approach of Machado and Mata (2005).

Here, we focus on the interpretation of the estimated gender gap in the mobility variables. The results show that the wage gains of males from occupational mobility are generally higher than for females, e.g. for the first cohort mobility

\footnotetext{
${ }^{15}$ The problem is that with the change in the set of covariates, it is not possible to relate the quantiles of the different conditional distributions ("Quantiles can not be easily aggregated"). Also, the specification reported in table 6 imposes the same coefficients for both genders except for the experience and mobility variables.
} 
in the first year results in a 4.1 ppoints (difference $-0.012+0.053$ ) higher average wage gain for males than for females. This gender gap increases to 11.1 ppoints during years 7 to 9 . The gender gap differs strongly across the distri-

bution. Whereas males experience much higher wage gains than females in the lower part of the distribution, the gender gap is close to zero (and even negative for low experience) in the upper part of the wage distribution. This pattern also applies for the second cohort, but generally the gender gap is smaller than for the first cohort. For the last cohort, the gender gap has reversed for low experience with wage gains being higher for females compared to males and gains which are not significantly different from zero for higher experience. Thus, the wage gains associated with mobility changed considerably across the three cohorts and these changes must have contributed to the reduction in the gender wage gap by experience, especially in the lower part of the distribution.

\subsubsection{Gender wage gap if women exhibited male training occupations and male mobility patterns}

To investigate the extent to which the gender wage gap by experience can be attributed to the gender differences in the choice of training occupations and in the mobility pattern, we estimate quantile regressions for wages based solely on the female sample, i.e. no coefficient is restricted to be the same for both genders. Then, applying the Machado and Mata (2005) decomposition technique (as described in the methodological part of the appendix), we simulate the counterfactual sample of wages where females exhibit male characteristics regarding occupational covariates but are still 'paid like females'. Then, we add the actual male sample to this simulated sample and reestimate the wage regressions without occupational covariates. This way, we decompose the effects of differences in covariates and in coefficients on the unconditional gender specific wage distributions (quantiles). Extending the method to decompose the gender wage gap by experience levels, we determine to what extent the gender differences by experience without controlling for occupational covariates reflect gender differences in training occupations and occupational mobility.

Table 7 provides the regression results on the gender wage gap by experience. For all cohorts, the gender wage gap is considerably reduced compared to the 
first set of results in table 6, except for the lower part of the distribution for the 78-80 cohort. The reduction in the gender wage gap is higher in the upper part of the distribution which corresponds to the findings above on gender differences in wage gains across the distribution and it tends to increase with experience (especially in the upper part of the distribution). The reduction in the gender wage gap increases across cohorts and this effect is also stronger in the upper part of the distribution compared to the lower part of the distribution.

For women in the first cohort who earn low wages, copying male choices of training occupation and male mobility patterns would not have overcome their low wage career. The gender wage gap did persist because women with low wages did not have the same returns on the training occupation and to occupational mobility compared to males in the lower part of the wage distribution. Over time, women would gain more. They would gain more in the upper part of the wage distribution if they became more similar to male workers regarding their choice of training occupation and mobility patterns. Put together, changes in mobility patterns and changes in the wage gains associated with mobility have contributed to the reduction in the gender wage gap. Yet, in the most recent cohort, women could gain even more by copying male training occupations and mobility patterns.

$<$ Table 7 about here $>$

\subsection{Potential selection issues}

Our empirical analysis is mainly descriptive in analyzing the relationship between occupational segregation, occupational mobility, and the gender wage gap. We see three important potential problems with our analysis. First, this paper can not explain the gender differences in the choice of training occupation. Second, we do not attempt to model occupational mobility and wages jointly. Third, gender differences in selection into employment might bias our results.

Regarding the first issue, our data have no information on the household context (family background), on social attitudes (Fortin, 2005), or on the time in school (except for an indicator for Abitur) before the beginning of the apprenticeship. In addition, the regional industry structure is likely to have an impact on 
the supply of apprenticeship positions. These points make clear that it is close to impossible to model jointly the decision of doing an apprenticeship at all together with the choice of training occupation at the two-digit-level. Thus, our analysis has to take the choice of training occupation as given and we can only provide indirect evidence on how this choice interacts with wages and occupational mobility. Unobserved gender differences in ability could cause a spurious relationship between occupational segregation and the entry wage gap explaining the gender gap in entry wages. Based on the evidence that girls do not tend to do worse in secondary school (OECD, 2004, indicator A9), we assume that on average there are no unobserved gender differences in ability.

Second, we observe vast differences in the timing of occupational mobility after the end of the apprenticeship. We are interested in the relationship between occupational mobility and the position in the wage distribution by experience conditional on characteristics at entry. Modelling jointly the time path of occupational mobility and wages would be extremely difficult to implement. To some extent, we account for the simultaneity of wages and occupational choices using the panel nature of the data. We investigate whether the entry wage explains occupational mobility and we estimate the effects of occupational mobility on wages by a difference-in-differences estimator. This way, we address the possibility that permanent unobserved differences, which affect both wages and occupational mobility, matter for the estimated relationship between occupational mobility and the gender wage gap.

Third, when studying the effect of experience and mobility on the gender wage gap, one might be concerned about gender differences in selection into employment. For instance, if females with low wages tended to leave the labor market to a larger extent than males this might cause a spurious reduction of the gender wage gap. Table 8 provides regression evidence on gender differences in the accumulated non-employment time during the first eight years after the start of the first job following after apprenticeship. Females experience less time in non-employment than males. Without controlling for the training occupation (specification 1), males spent between one fifth of a year (cohort 90-93) and half a year (cohort 78-80) more time in non-employment than females. ${ }^{16}$ Similar to

\footnotetext{
${ }^{16}$ Note that this effect can be the result of the mandatory military service for males. The
} 
the results by Light and Ureta (1992), young female workers after apprenticeship do not exhibit a higher risk of quitting the labor market. Including dummies for training occupations (specification 2) slightly reduces the gender difference. We conclude that selection into employment is not likely to cause an important bias for our analysis in sections 4.1 and 4.2 ..

Finally, note that the results in table 8 are also interesting regarding some of the aspects discussed in section 2. Specification (2) in table 8 controls for training occupations. The gender effect is only slightly reduced compared to specification (1). Thus, there is no evidence that gender differences in employment interruptions are strongly associated with certain occupations allowing for more career interruptions. The estimated wage effects (specification 3) are quite interesting. The average entry wage in the training occupation as well as the individual position in the first job exert a significant negative effect on time spent in non-employment. The higher the entry wage the less likely it is that outside opportunities dominate work.

$<$ Table 8 about here $>$

\section{Summary and Conclusions}

This paper investigates the relationship between the gender wage gap, the choice of training occupations and occupational mobility. We use longitudinal data on a sample of young workers with apprenticeship training (denoted as skilled workers) in West Germany. Our analysis is also of interest to any country which has implemented or considers implementing a formalized work based training system with the goal to smooth the transition from school to work. Such a system has strong effects on gender differences in labor market careers. Workers make occupational career choices early during their careers and women and men pursue very different occupational careers. We reconsider whether through occupational segregation women are locked in low wage careers (Kunze, 2005) or whether they can raise up to higher wage paths through mobility. Furthermore, our analysis investigates whether patterns have changed across cohorts during the period 1978

effect can not be related to a gender difference in tertiary education after vocational training, a widespread phenomenon in Germany, since our data set excludes those workers. 
and 2001 and whether effects vary across the wage distribution. We consider the labor market experience of three training cohorts defined by year of completion of the apprenticeship. These are the cohorts 1978-80, 1984-84, and 1990-93.

Similar to previous results, we find a persistent gender wage gap over the first ten years of work experience which is higher in the lower part of the wage distribution. The gender wage gap decreases over time, especially in the lower part of the wage distribution. Occupational segregation by gender, however, persists over time, both regarding training occupation and occupation of work. Females exhibit less occupational mobility than males, which for the two later training cohorts is completely explained by the training occupation. Thus, females are concentrated in training occupations with low occupational mobility rates.

Occupational mobility is associated with positive wage gains and occupational mobility is slightly higher for workers with lower wages in the training occupation. The gain from mobility is lower for females than for males in the lower part of the wage distribution, while wage gains are similar for both genders in the upper part. Correspondingly, female workers are often locked in low wage careers, since males are more likely to change occupation and benefit from the associated wage gains. Occupational mobility does not overcome occupational segregation and the reduction in the gender wage gap is not caused by a reduction in occupational segregation itself.

Nevertheless, for the training cohorts in the 1990s, female mobility rates have converged to male rates in the same training occupation and the wage gains due to occupational mobility have increased for females relative to males. Both effects have reduced the gender wage gap, compared to the late 1970s to 1980s training cohorts. However, if females exhibited the same training occupations and the same mobility patterns as males, the gender wage gap would be reduced considerably further, especially in the upper part of the distribution where the wage gains due to mobility are higher. The evidence suggests that lock-in effects associated with occupational segregation are very important in explaining the gender wage gap among skilled workers in Germany. This is especially important in the upper part of the wage distribution since there women would have gained most from occupational mobility. However, for women with low wages, a substantial wage disadvantage would remain even if they were similar to males regarding training 
occupations and occupational mobility. Put differently, even with higher occupational mobility, women with low wages tend to be locked in low wage careers. Our study shows that occupational segregation and lower occupational mobility among females explains the gender wage gap to a considerable extent but this differs across the wage distribution.

The observed reduction in the gender wage gap across training cohorts is likely to be related to changes in social attitudes regarding gender roles in the labor market as discussed by Fortin (2005), an issue we could not explore here. In further research, it would be of great interest to quantify the importance of social attitudes for the extent of occupational segregation and the gender differences in occupational mobility.

\section{References}

Albrecht, J., A. Björklund, and S. Vroman (2003) Is there a Glass Ceiling in Sweden? Journal of Labor Economics, 21(1), 145-177.

Altonji, J.G. and R.M. Blank (1999) Race and Gender in the Labor Market, in: Handbook of Labor Economics, Volume 3, 3143-3259.

Barron, J.M., D.A. Black, and M.A. Loewenstein (1993) Gender differences in training, capital, and Wages. Journal of Human Resources, 28(2), 343-364.

Bender, S., A. Haas, and C. Klose (2000). "IAB employment subsample 19751995”, Schmollers Jahrbuch, 120, 649-662.

Blinder, A. (1973) Wage discrimination: reduced forms and structural estimates. Journal of Human Resources, 8(4), 436-454.

Brown, Charles, and Mary Corcoran (1997). Sex-based differences in school content and the male-female wage gap. Journal of Labor Economics. 15(3). pp.431-465.

Dolado, J., F. Felgueroso and J.F. Jimeno (2001) Female employment and occupational changes in the 1990s: How is the EU performing relative to the US?, European Economic Review, 45, 875-879. 
Dolado, J., F. Felgueroso and J.F. Jimeno (2003) Where do women work? Analysing patterns in occupational segregation by gender, Annales d'Economie et Statistique, 71/72, pp. 267-292.

Euwals, R. and R. Winkelmann (2002) Mobility after Apprenticeship - Evidence from Register Data. Applied Economics Quarterly, 48(3-4), 256-278.

Fahr, R. (2003), Occupational Mobility and Occupational Match: Some Implications for Career Choice and Labor Market Policy, Dissertation, Universität Bonn.

Fitzenberger, B. and A. Spitz (2004): Die Anatomie des Berufswechsels: Eine empirische Bestandsaufnahme auf Basis der BIBB/IAB-Daten 1998/1999. In: Franz, W., Ramser, H.J. and M. Stadler, eds, 'Bildung', J.C.B. Mohr (Paul Siebeck) Tübingen, Schriftenreihe des wirtschaftswissenschaftlichen Seminars Ottobeuren, 2004.

Fitzenberger, B. and G. Wunderlich (2002) Gender Wage Differences in West Germany: A Cohort Analysis", German Economic Review, 3(4), 379-414.

Fortin, N. (2005) Gender Role Attitudes and the Labour Market Outcomes of Women Across OECD Countries. Oxford Review of Economic Policy (forthcoming).

Kangasniemi, M. (2004) Occupational assignment, wage, and gender in Finnish Manufacturing. Unpublished Manuscript, London School of Economics.

Kuhn, P. (1993) Demographic Groups and Personnel Policy. Labour Economics, $1(1), 49-70$.

Kunze, A. (2003): Gender Differences in Entry Wages and Early Career Wages, Annales d'Economie et Statistique, 71/72, pp. 245-266.

Kunze, A. (2005) The Evolution of the Gender Wage Gap, Labour Economics, 12, pp.73-97, 2005.

Light, A. and M. Ureta (1992) Panel Estimates of Male and Female Job Turnover Behavior: Can Female Nonquitters be identified? Journal of Labor Economics, 10, 156-181. 
Light, Audrey, and Ureta, Manuelita (1995). Early-career work experience and gender wage differentials. Journal of Labor Economics. 13(1). pp.121-154.

Loprest, P.J. (1992) Gender Differences in Wage Growth and Job Mobility. American Economic Review, 82(2), 526-532.

Machado, J. and Mata, J. (2005) Counterfactual Decomposition of Changes in Wage Distributions Using Quantile Regression. Journal of Applied Econometrics (forthcoming).

Miller, P. (1987) The wage effect of occupational segregation of women in Britain. Economic Journal, 97, 885-896.

Münch, J. (1992) Das Berufsbildungssystem in der Bundesrepublik Deutschland. European Centre for the Development of Vocational Training (CEDEFOP), Berlin.

OECD (2004) Education at a Glance - OECD Indicators. OECD, Paris.

Oaxaca, Ronald (1973). Male-female wage differentials in urban labor markets. International Economic Review. 14(3). pp.693-709.

Paglin, M. and A.M. Rudolfo (1990) Heterogeneous Human Capital, Occupational Choice, and Male-Female Earnings Differences. Journal of Labor Economics, 8(1), 123-144 (Part 1).

Polachek, S.W. (1981) Occupational Self-Selection: A Human Capital Approach to Sex Differences in Occupational Structure. Review of Economics and Statistics, 63(1), 60-69.

Royalty, A.B. (1996) The Effects of Job Turnover on the Training of Men and Women. Industrial and Labor Relations Review, 49(3), 506-521.

Topel. R.H. and M.P. Ward (1992) Job Mobility and the Careers of Young Men. The Quarterly Journal of Economics, 439-479.

Werwatz, A. (2002) Mobility after Apprenticeship: How effective is the German Apprenticeship System? Applied Economics Quarterly, 48(3-4), 279-303. 


\section{Appendix}

\section{Methodological Aspects}

\section{Normalization of interaction terms to obtain average gender differences}

As an illustration, consider the regression of some response variable $y_{i, \exp }$ for individual $i$ with experience level exp on covariates indicating dummy variables for (integer years) of experience and mobility dummy variables 'Move' interacted with dummy variables for integer years of experience when mobility took place Exper $M$. Taking just two dummy variables for experience, the regression would be

$$
\begin{gathered}
y_{i, \exp }=\beta_{1} \cdot D E X P_{0}+\beta_{2} \cdot D E X P_{1-3}+\beta_{3} \cdot \text { Move } \cdot D E X P M_{0}+ \\
\beta_{4} \cdot \text { Move } \cdot D E X P M_{1-3}+\gamma_{1} \cdot D E X P_{0} \cdot \text { Male }+\gamma_{2} \cdot D E X P_{1-3} \cdot \text { Male } \\
+\gamma_{3} \cdot \text { Move } \cdot D E X P M_{0} \cdot \text { Male }+\gamma_{4} \cdot \text { Move } \cdot D E X P M_{1-3} \cdot \text { Male }
\end{gathered}
$$

where the error term is omitted. $y_{i, \exp }$ represents variable $y$ observed for individual $i$ at experience level exp. $D E X P_{k}$ is a dummy corresponding to $k=0$ or $1-3$ years of experience, respectively. Move is a dummy for occupational mobility having taken place before. $D E X P M_{k}$ is a dummy variable indicating the experience level when mobility occurs.

The goal is to normalize the interaction terms such that the gender gap (male minus female) by experience level $\gamma_{1}$ and $\gamma_{2}$ provides the estimated average gender gap (average partial effect of gender) by experience level, e.g. $\gamma_{1}$ should correspond to the average gender difference among workers with 0 years of experience among both movers and stayers. Formally, the estimated average gender gap for workers for 0 years of experience is

$$
\frac{1}{N_{m, 0}} \sum_{i_{m}=1}^{N_{m, 0}} \hat{y}_{i\left(i_{m}\right)}-\frac{1}{N_{f, 0}} \sum_{i_{f}=1}^{N_{f, 0}} \hat{y}_{i\left(i_{f}\right)}
$$

where $N_{m, 0}$ and $N_{f, 0}$ are the number of male and female workers with 0 years of experience, respectively, $i\left(i_{m}\right)$ and $i\left(i_{f}\right)$ correspond to the individual male and female workers, and $\hat{y}$. the fitted values. Plugging in the regression estimates, the 
average gender gap for the example used here is

$$
\begin{aligned}
& =\frac{1}{N_{m, 0}} \sum_{i_{m}=1}^{N_{m, 0}}\left(\beta_{1}+\gamma_{1}+\beta_{3} \text { Move } \cdot D E X P M_{0}+\gamma_{3} \text { Move } \cdot D E X P M_{0}\right) \\
& \left.-\frac{1}{N_{f, 0}} \sum_{i_{f}=1}^{N_{f, 0}}\left(\beta_{1}+\beta_{3} \text { Move } \cdot \operatorname{DEXP} M_{0}\right)\right)
\end{aligned}
$$

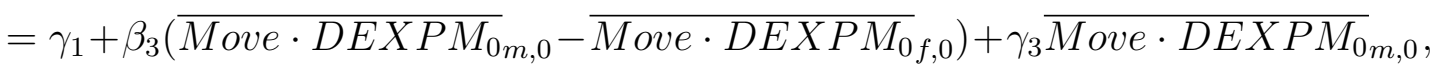

where $\overline{\text { Move } \cdot D E X P M_{0}, 0}(\mathrm{~g}=\mathrm{m}, \mathrm{f})$ are the the gender and experience specific averages of the covariate Move. $D E X P M_{0}$. Thus, we normalize the interaction terms $D E X P M_{k} \cdot$ Move (and any other interactions with gender dummies) by subtracting the gender and experience specific averages $\overline{M o v e \cdot D E X P M_{0 g}}, k$ $(\mathrm{g}=\mathrm{m}, \mathrm{f}$ and $\mathrm{k}=0,1-3)$. Then the estimated average gender gap in the response variable (average partial effect of gender) by experience level $k$ corresponds to $\gamma_{k}$.

\section{Machado and Mata Decomposition Technique}

For quantile regression, it is not possible to relate conditional quantiles based on a finer set of covariates to conditional quantiles based on a coarser set of covariates. Machado and Mata (2005), M\&M, suggest a simulation based method to decompose the effects of differences in covariates and in coefficients on the unconditional gender specific wage distributions to investigate the determinants of the distributional (quantile specific) wage gap. ${ }^{17}$ As described in the following, the M\&M technique can be readily extended to the decomposition of the gender wage gap by experience levels in a regression context. Using this extension of the M\&M technique, we determine to what extent the gender differences by experience reported in table 6 without the occupational covariates reflect gender differences in training occupations and occupational mobility.

The idea of the simulation approach used here is to generate a counterfactual sample of wages where females exhibit male characteristics but are still 'paid like females'. Then, we add the actual male sample to this simulated sample and reestimate the wage regressions without occupational covariates. The resulting

\footnotetext{
${ }^{17}$ The decomposition technique by Machado/Mata (2005) is an extension of the well know Blinder/Oaxaca (see Blinder, 1973) decomposition technique for quantile regression.
} 
gender wage gap by experience is corrected for differences in these occupational covariates (and only these because we still control for experience and characteristics at entry). The counterfactual simulation is based on coefficient estimates based only on the female sample. In contrast, the second set of estimates in table 6 (with occupational variables), estimates the same coefficients for males and females for all covariates except experience and the mobility variables.

Based on the simplication of the M\&M techniques suggested in Albrecht et al. (2002), we use the following procedure to simulate the counterfactual sample for females:

1. Using the original female data set, estimate the quantile regression coefficient vector $\beta^{f}(\theta)$ for each percentile $\theta=.01, .02, \ldots, .99$.

2. Using the male sample, draw independently for each observation $i$ in this sample a corresponding percentile $\theta_{i}$ from the uniform, discrete distribution on all percentiles $\theta=.01, .02, \ldots, .99$.

3. The counterfactual wages for females in the sample with the male characteristics (the initial male sample) are then generated as $\left\{\log \left(w_{i}^{*}\right)=x_{i}^{m} \beta^{f}\left(\theta_{i}\right)\right\}$. 


\section{Tables and Figures}

Table 1: Coding of Consolidated 2-digit Occupation Variable occ2d

\begin{tabular}{|c|c|c|}
\hline Consolidated 2-digit code & $\begin{array}{l}\text { Comprises the } \\
\text { following 2-digit } \\
\text { occupations }\end{array}$ & $\begin{array}{l}\text { Comprises the } \\
\text { following val- } \\
\text { ues of variable } \\
\text { 'beruf' (occorg) } \\
\text { in IABS }\end{array}$ \\
\hline 1 & $1-4$ & 1,2 \\
\hline 5 & 5,6 & 3,4 \\
\hline 7 & $7-9$ & 5 \\
\hline 10 & 10,11 & 6 \\
\hline 12 & 12,13 & 7 \\
\hline 14 & 14 & 8,9 \\
\hline 15 & 15 & 10 \\
\hline 16 & 16 & 11 \\
\hline 17 & 17 & 12 \\
\hline 18 & 18 & 13 \\
\hline 19 & 19 & 14 \\
\hline 20 & 20 & 15 \\
\hline 21 & 21 & 16 \\
\hline 22 & 22 & $17-19$ \\
\hline 23 & 23 & 20 \\
\hline 24 & 24 & 21 \\
\hline 25 & 25,26 & 22,23 \\
\hline 27 & 27 & $24-27$ \\
\hline 28 & 28 & $28-30$ \\
\hline 29 & 29 & 31 \\
\hline 30 & 30 & 32 \\
\hline 31 & 31 & $33-35$ \\
\hline 32 & 32 & $36-38$ \\
\hline
\end{tabular}

Continued on next page 


\begin{tabular}{|c|c|c|}
\hline Consolidated 2-digit code & $\begin{array}{l}\text { Comprises the } \\
\text { following 2-digit } \\
\text { occupations }\end{array}$ & $\begin{array}{l}\text { Comprises the } \\
\text { following val- } \\
\text { ues of variable } \\
\text { 'beruf' (occorg) } \\
\text { in IABS }\end{array}$ \\
\hline 33 & 33,34 & 39 \\
\hline 35 & 35,36 & 40,41 \\
\hline 37 & 37 & 42 \\
\hline 39 & 39 & 43 \\
\hline 40 & 40 & 44 \\
\hline 41 & 41 & 45 \\
\hline 42 & 42,43 & 46 \\
\hline 44 & 44 & 47,48 \\
\hline 45 & 45 & 49,50 \\
\hline 46 & 46 & 51 \\
\hline 47 & 47 & 52,53 \\
\hline 48 & 48 & 54 \\
\hline 49 & 49 & 55 \\
\hline 50 & 50 & 56 \\
\hline 51 & 51 & 57,58 \\
\hline 52 & 52 & 59,60 \\
\hline 54 & 54 & 62 \\
\hline 60 & 60 & $63-67$ \\
\hline 61 & 61,62 & $68-73$ \\
\hline 63 & 63 & $74-75$ \\
\hline 68 & 68 & $76-79$ \\
\hline 69 & 69 & 80,81 \\
\hline 70 & 70 & 82,83 \\
\hline 71 & 71 & $84-86$ \\
\hline 72 & 72 & 87 \\
\hline 73 & 73 & 88,89 \\
\hline 74 & 74 & $90-92$ \\
\hline
\end{tabular}

Continued on next page 


\begin{tabular}{|c|c|c|}
\hline Consolidated 2-digit code & $\begin{array}{l}\text { Comprises the } \\
\text { following 2-digit } \\
\text { occupations }\end{array}$ & $\begin{array}{l}\text { Comprises the } \\
\text { following val- } \\
\text { ues of variable } \\
\text { 'beruf' (occorg) } \\
\text { in IABS }\end{array}$ \\
\hline 75 & 75 & 93,94 \\
\hline 76 & 76 & 95 \\
\hline 77 & 77 & 96-99 \\
\hline 78 & 78 & $100-103$ \\
\hline 79 & $79-81$ & $104-106$ \\
\hline 82 & 82 & 107 \\
\hline 83 & 83 & 108 \\
\hline 84 & 84 & 109 \\
\hline 85 & 85 & $110-114$ \\
\hline 86 & 86 & $115-117$ \\
\hline 87 & 87 & 118,119 \\
\hline 88 & 88 & 120 \\
\hline 90 & 90 & 121 \\
\hline 91 & 91 & $121-124$ \\
\hline 92 & 92 & 125 \\
\hline 93 & 93 & $126-129$ \\
\hline 98 & 98 & 61,130 \\
\hline
\end{tabular}

Note: The information for this table is taken from the data description for the IAB employment subsample and the content under the label "Berufe im Spiegel der Statistik" on http://www.pallas.iab.de/bisds/berufsgliederung.asp . 
Table 2: Sample size, by cohort group and sex

\begin{tabular}{|c|c|c|c|}
\hline Years of experience & Cohorts 1978-80 & Cohorts 1984-86 & Cohorts 1990-93 \\
\hline \multicolumn{4}{|l|}{ Women } \\
\hline 0 & 11,482 & 17,679 & 22,568 \\
\hline 1 & 7,977 & 11,232 & 12,461 \\
\hline 2 & 6,944 & 10,146 & 11,033 \\
\hline 3 & 6,180 & 9,077 & 9,840 \\
\hline 4 & 5,684 & 8,219 & 8,834 \\
\hline 5 & 4,980 & 7,256 & 7,766 \\
\hline 6 & 4,406 & 6,265 & 0 \\
\hline 7 & 3,839 & 5,448 & 0 \\
\hline 8 & 3,319 & 4,765 & 0 \\
\hline 9 & 2,858 & 4,086 & 0 \\
\hline 10 & 2,428 & 3,502 & 0 \\
\hline \multicolumn{4}{|l|}{ Men } \\
\hline 0 & 19,288 & 25,540 & 25,827 \\
\hline 1 & 15,596 & 18,101 & 14,762 \\
\hline 2 & 12,536 & 15,772 & 12,686 \\
\hline 3 & 11,375 & 14,464 & 11,349 \\
\hline 4 & 10,664 & 13,377 & 10,327 \\
\hline 5 & 10,051 & 12,426 & 9,199 \\
\hline 6 & 9,573 & 11,674 & 0 \\
\hline 7 & 9,134 & 11,051 & 0 \\
\hline 8 & 8,814 & 10,542 & 0 \\
\hline 9 & 8,405 & 9,829 & 0 \\
\hline 10 & 8,088 & 9,339 & 0 \\
\hline
\end{tabular}

Note: West German sample of young skilled workers extracted from the IABS-R01 employment statistic. We collapsed the data into integers of years of work experience. Hence, zero includes entry wages as well as spells with accumulated work experience shorter than 1 year. 
Table 3: Skilled women in first job - means and standard deviations

\begin{tabular}{lrrrrrrr}
\hline cohort & $\begin{array}{r}\text { medium } \\
\text { degree }\end{array}$ & Abitur & $\begin{array}{r}\text { years of } \\
\text { training }\end{array}$ & age & $\begin{array}{r}\text { years of } \\
\text { transition }\end{array}$ & $\begin{array}{r}\mathbf{1} \text { if } \\
\text { stayer }\end{array}$ & $\begin{array}{r}\text { number of } \\
\text { observations }\end{array}$ \\
\hline $1978-80$ & 0.99 & 0.01 & 2.51 & 19.28 & 0.04 & 0.77 & 9168 \\
$1984-93$ & $(0.09)$ & $(0.09)$ & $(0.51)$ & $(1.06)$ & $(0.17)$ & $(0.42)$ & \\
& 0.95 & 0.05 & 2.61 & 20.34 & 0.04 & 0.75 & 11925 \\
$1990-93$ & $(0.21)$ & $(0.21)$ & $(0.60)$ & $(1.54)$ & $(0.17)$ & $(0.43)$ & \\
& 0.91 & 0.09 & 2.78 & 20.85 & 0.05 & 0.77 & 10692 \\
Total & $(0.28)$ & $(0.28)$ & $(0.64)$ & $(1.65)$ & $(0.19)$ & $(0.42)$ & \\
& 0.95 & 0.05 & 2.65 & 20.29 & 0.04 & 0.76 & \\
& $(0.23)$ & $(0.23)$ & $(0.61)$ & $(1.61)$ & $(0.18)$ & $(0.42)$ & \\
\hline
\end{tabular}

Note: West-German sample of young skilled workers extracted from the IABS-R01 employment subsample. Standard errors are reported in parentheses.

Table 4: Skilled men in first job - means and standard deviations

\begin{tabular}{lrrrrrrr}
\hline cohort & $\begin{array}{r}\text { medium } \\
\text { degree }\end{array}$ & Abitur & $\begin{array}{c}\text { years of } \\
\text { training }\end{array}$ & age & $\begin{array}{r}\text { years of } \\
\text { transition }\end{array}$ & $\begin{array}{r}\text { 1 if } \\
\text { stayer }\end{array}$ & $\begin{array}{r}\text { number of } \\
\text { observations }\end{array}$ \\
\hline $1978-80$ & 1.00 & 0.00 & 2.69 & 19.30 & 0.05 & 0.76 & 6214 \\
& $(0.06)$ & $(0.06)$ & $(0.51)$ & $(1.02)$ & $(0.20)$ & $(0.42)$ & \\
$1984-86$ & 0.98 & 0.02 & 2.78 & 20.21 & 0.06 & 0.69 & 9203 \\
& $(0.14)$ & $(0.14)$ & $(0.59)$ & $(1.47)$ & $(0.25)$ & $(0.46)$ & \\
$1990-93$ & 0.95 & 0.05 & 2.98 & 20.91 & 0.11 & 0.68 & 10697 \\
& $(0.23)$ & $(0.23)$ & $(0.67)$ & $(1.65)$ & $(0.33)$ & $(0.47)$ & \\
Total & 0.97 & 0.03 & 2.82 & 20.18 & 0.07 & 0.71 & \\
& $(0.16)$ & $(0.16)$ & $(0.61)$ & $(1.56)$ & $(0.27)$ & $(0.46)$ & \\
\hline
\end{tabular}

Note: West German sample of young skilled workers extracted from the IABS-R01 employment subsample. Standard errors are reported in parentheses. 
Table 5: Probability for not working in training occupation during first ten years of work experience - Gender differences by experience and wage effects

\begin{tabular}{|c|c|c|c|}
\hline Specification & (1) & $(2)$ & (3) \\
\hline Covariate & Coeff. & Coeff. & Coeff. \\
\hline \multicolumn{4}{|c|}{ Cohort 1978-80 } \\
\hline \multirow[t]{2}{*}{ Male $\times D E X P_{0}$} & .0299 & .0065 & .0325 \\
\hline & $(.0053)$ & $(.0061)$ & $(.0053)$ \\
\hline \multirow[t]{2}{*}{ Male $\times D E X P_{1-3}$} & .0568 & .0311 & .0605 \\
\hline & $(.0040)$ & $(.0049)$ & $(.0040)$ \\
\hline \multirow[t]{2}{*}{ Male $\times D E X P_{4-6}$} & .1135 & .0797 & .1173 \\
\hline & $(.0048)$ & $(.0055)$ & $(.0047)$ \\
\hline \multirow[t]{2}{*}{ Male $\times D E X P_{7-9}$} & .1530 & .1122 & .1567 \\
\hline & $(.0057)$ & $(.0062)$ & $(.0056)$ \\
\hline \multirow{2}{*}{$\begin{array}{l}\text { Average log entry wage for males } \\
\text { in training occupation }\end{array}$} & - & - & -.0947 \\
\hline & & & $(.0090)$ \\
\hline \multirow{2}{*}{$\begin{array}{l}\text { Individual log entry wage minus } \\
\text { average log entry wage for males }\end{array}$} & - & - & .0239 \\
\hline & & & $(.0036)$ \\
\hline \multirow{2}{*}{$\begin{array}{l}\text { Average log entry wage for females } \\
\text { in training occupation }\end{array}$} & - & - & -.2702 \\
\hline & & & $(.0078)$ \\
\hline \multirow{2}{*}{$\begin{array}{l}\text { Individual log entry wage minus } \\
\text { average log entry wage for females }\end{array}$} & - & - & .0619 \\
\hline & & & $(.0051)$ \\
\hline \multicolumn{4}{|c|}{ Cohort 1984-86 } \\
\hline \multirow[t]{2}{*}{ Male $\times D E X P_{0}$} & .0824 & .0047 & .0871 \\
\hline & $(.0045)$ & $(.0050)$ & $(.0045)$ \\
\hline \multirow[t]{2}{*}{ Male $\times D E X P_{1-3}$} & .0837 & .0011 & .0892 \\
\hline & $(.0034)$ & $(.0040)$ & $(.0034)$ \\
\hline \multirow[t]{2}{*}{ Male $\times D E X P_{4-6}$} & .0916 & -.0008 & .0976 \\
\hline & $(.0042)$ & $(.0046)$ & $(.0041)$ \\
\hline \multirow[t]{2}{*}{ Male $\times D E X P_{7-9}$} & .1027 & .0050 & .1089 \\
\hline & $(.0049)$ & $(.0052)$ & $(.0049)$ \\
\hline
\end{tabular}

Continued on next page 


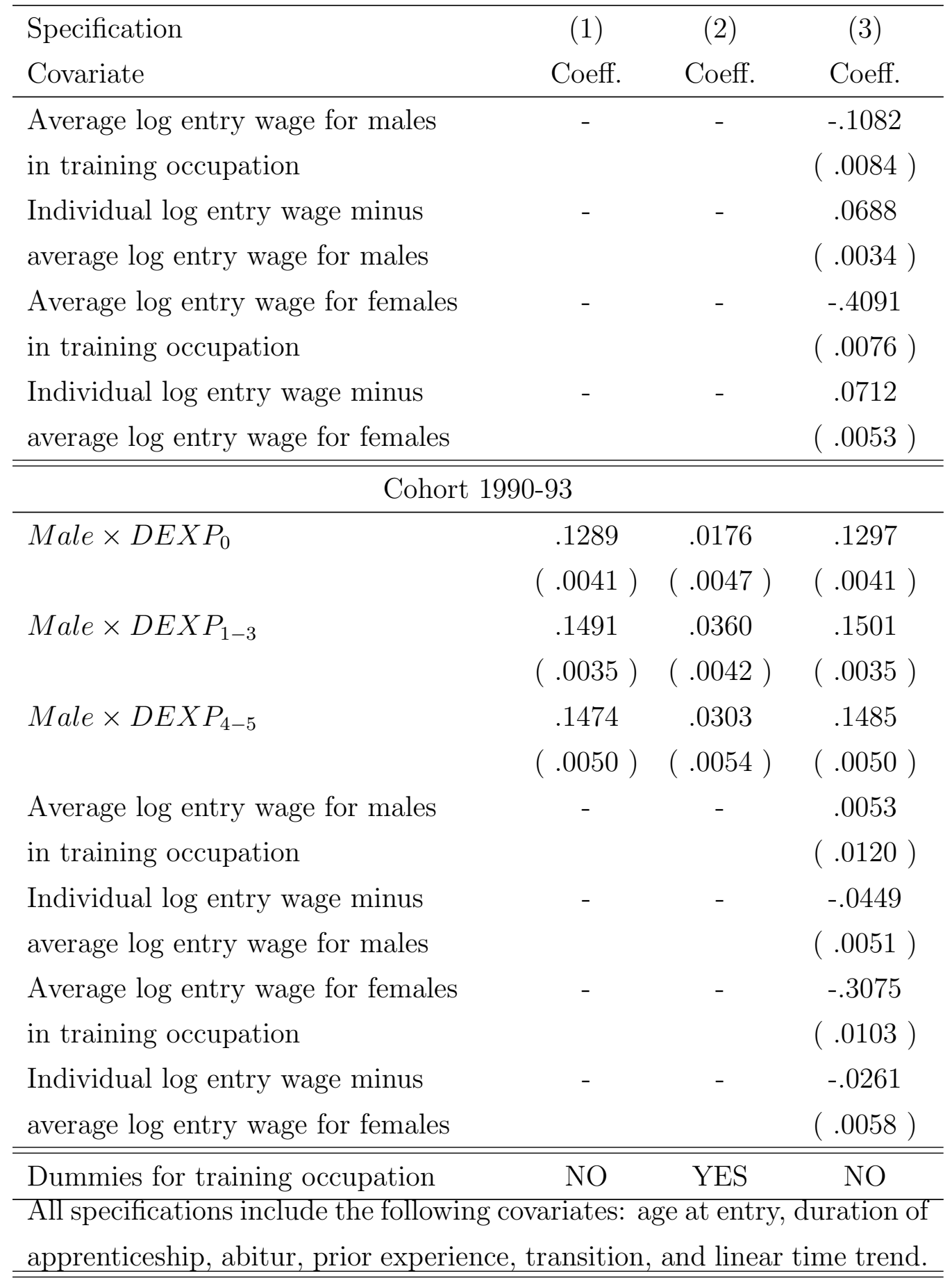

Note: The table comprises the coefficient estimates for the gender variables in an OLS regression of the dummy of a change of 2-digit occupation (occupation of work differs from training occupation) during the first ten years of work experience after the end of the apprenticeship. Heteroscedasticity-consistent standard errors 
are reported in parentheses. For the entry wage, we use the wage in the first employment spell after the end of the apprenticeship irrespective of whether the occupation of work is the same as the training occupation. For all interaction terms of wage variables with gender dummies, the wage variable is normalized such that the estimated coefficients for the gender-experience dummy variables reflect the average gender difference for this experience level holding all other covariates constant, see section on methodological aspects in appendix for details. 
Table 6: (a) Gender wage gap by work experience controlling for a number of characteristics at entry - training cohort 1978-80

\begin{tabular}{|c|c|c|c|c|c|c|c|c|}
\hline \multirow[t]{2}{*}{ Covariates } & \multicolumn{2}{|c|}{ OLS } & \multicolumn{2}{|c|}{ QR $20 \%$} & \multicolumn{2}{|c|}{ QR $50 \%$} & \multicolumn{2}{|c|}{ QR $80 \%$} \\
\hline & Coeff. & (s.e.) & Coeff. & (s.e.) & Coeff. & (s.e.) & Coeff. & (s.e.) \\
\hline \multicolumn{9}{|c|}{ without occupation/mobility dummies } \\
\hline \multicolumn{9}{|c|}{ Experience in years interacted with male } \\
\hline$D E X P_{0}$ & .2069 & $(.0039)$ & .1511 & $(.0070)$ & .2343 & $(.0026)$ & .1973 & $(.0065)$ \\
\hline$D E X P_{1-3}$ & .2793 & $(.0026)$ & .3498 & $(.0045)$ & .2421 & $(.0017)$ & .2041 & $(.0042)$ \\
\hline$D E X P_{4-6}$ & .2908 & $(.0030)$ & .3544 & $(.0050)$ & .2303 & $(.0018)$ & .2125 & $(.0047)$ \\
\hline$D E X P_{7-9}$ & .3046 & $(.0034)$ & .3891 & $(.0058)$ & .2249 & $(.0021)$ & .1960 & $(.0054)$ \\
\hline \multicolumn{9}{|c|}{ with occupation/mobility dummies } \\
\hline \multicolumn{9}{|c|}{ Experience in years interacted with male } \\
\hline$D E X P_{0}$ & .1382 & $(.0041)$ & .0458 & $(.0071)$ & 1387 & $(.0027)$ & .2038 & $(.0069)$ \\
\hline$D E X P_{1-3}$ & .2128 & $(.0030)$ & .1919 & $(.0050)$ & .1846 & $(.0019)$ & .2077 & $(.0048)$ \\
\hline$D E X P_{4-6}$ & .2378 & $(.0033)$ & .2150 & $(.0054)$ & .1804 & $(.0020)$ & .2157 & $(.0052)$ \\
\hline$D E X P_{7-9}$ & .2557 & $(.0037)$ & .2349 & $(.0059)$ & .1749 & $(.0022)$ & .1988 & $(.0057)$ \\
\hline \multicolumn{9}{|c|}{ Mobility effects interacted with male } \\
\hline Move $\times D E X P M_{0}$ & -.0124 & $(.0177)$ & .0624 & $(.0370)$ & .0937 & $(.0138)$ & -.0764 & $(.0356)$ \\
\hline Move $\times D E X P M_{1-3}$ & .0186 & $(.0090)$ & .0365 & $(.0153)$ & -.0240 & $(.0057)$ & -.0381 & $(.0148)$ \\
\hline Move $\times D E X P M_{4-6}$ & .0966 & $(.0120)$ & .2138 & $(.0199)$ & .0616 & $(.0074)$ & .0016 & $(.0192)$ \\
\hline Move $\times D E X P M_{7-9}$ & .1090 & $(.0206)$ & .2173 & $(.0346)$ & .1155 & $(.0129)$ & -.0085 & $(.0334)$ \\
\hline Pre Move $\times D E X P M_{0}$ & -.0528 & $(.0176)$ & -.1058 & $(.0368)$ & -.1635 & $(.0137)$ & .0056 & $(.0355)$ \\
\hline Pre Move $\times D E X P M_{1-3}$ & -.0408 & $(.0077)$ & -.0650 & $(.0133)$ & -.0164 & $(.0050)$ & .0010 & $(.0128)$ \\
\hline Pre Move $\times D E X P M_{4-6}$ & .0136 & $(.0076)$ & .0128 & $(.0126)$ & .0285 & $(.0047)$ & .0243 & $(.0121)$ \\
\hline Pre Move $\times D E X P M_{7-9}$ & -.0026 & $(.0082)$ & -.0097 & $(.0133)$ & .0046 & $(.0050)$ & .0185 & $(.0128)$ \\
\hline \multicolumn{9}{|c|}{$\begin{array}{l}\text { All specifications include the following covariates: dummy variables for experience, } \\
\text { age at entry, duration of apprenticeship, abitur, prior experience, transition, and } \\
\text { linear time trend. }\end{array}$} \\
\hline \multicolumn{9}{|c|}{$\begin{array}{l}\text { 'Move' and 'PreMove' interacted with dummy variables for experience when first } \\
\text { occupational change occured. }\end{array}$} \\
\hline
\end{tabular}


Table 6: (b) Gender wage gap by work experience controlling for a number of characteristics at entry - training cohort 1984-86

\begin{tabular}{lllllllll}
\hline Covariates & \multicolumn{2}{c}{ OLS } & \multicolumn{2}{c}{ QR 20\% } & \multicolumn{2}{c}{ QR 50\% } & \multicolumn{2}{c}{ QR 80\% } \\
\hline & Coeff. & (s.e.) & Coeff. & (s.e.) & Coeff. & (s.e.) & Coeff. & (s.e.) \\
\hline
\end{tabular}

without occupation/mobility dummies

Experience in years interacted with male

\begin{tabular}{lcccccccc}
$\mathrm{DEX} P_{0}$ & .2144 & $(.0033)$ & .1959 & $(.0059)$ & .2390 & $(.0022)$ & .2013 & $(.0056)$ \\
$\mathrm{DEXP}_{1-3}$ & .2669 & $(.0023)$ & .3103 & $(.0039)$ & .2387 & $(.0014)$ & .2248 & $(.0037)$ \\
$\mathrm{DEXP}_{4-6}$ & .2280 & $(.0026)$ & .2518 & $(.0043)$ & .1881 & $(.0016)$ & .1743 & $(.0041)$ \\
$\mathrm{DEXP}$ & .2015 & $(.0030)$ & .2117 & $(.0050)$ & .1480 & $(.0018)$ & .1373 & $(.0047)$ \\
\multicolumn{6}{c}{ with } & occupation/mobility dummies & &
\end{tabular}

Experience in years interacted with male

$\begin{array}{lllllllll}\mathrm{DEXP} & .1562 & (.0034) & .0895 & (.0060) & .1666 & (.0022) & .1947 & (.0058) \\ \mathrm{DEXP}_{1-3} & .2145 & (.0026) & .1870 & (.0042) & .1860 & (.0016) & .2163 & (.0041) \\ \mathrm{DEXP}_{4-6} & .1835 & (.0028) & .1480 & (.0045) & .1396 & (.0017) & .1661 & (.0044) \\ \operatorname{DEX} P_{7-9} & .1609 & (.0031) & .1083 & (.0050) & .1036 & (.0019) & .1306 & (.0049)\end{array}$

Mobility effects interacted with male

\begin{tabular}{|c|c|c|c|c|c|c|c|c|}
\hline Move $\times D E X P M_{0}$ & 79 & & $B$ & 5) & .0033 & & 4 & \\
\hline Move $\times D E X P M_{1-3}$ & .0135 & $(0 \cap 76)$ & 0421 & $(.0128)$ & - & $(.0048)$ & -.0262 & 4) \\
\hline Move $\times D E X P M_{4-6}$ & .0329 & ;) & 4 & 57) & 283 & & 037 & \\
\hline Move $\times D E X P M_{7-9}$ & .1150 & $()$. & .0356 & $(.0323)$ & .048 & 1) & .0 & \\
\hline $\mathrm{ve} \times D E X P M_{0}$ &.-( & 0) & -.1100 & 364) & -.0632 & 36) & .0083 & \\
\hline ove $\times D E X P M_{1-3}$ & -.0197 & $(.0$ & -.04 & $0)$ & .00 & $($. & .01 & $(.010$ \\
\hline re Move $\times D E X P M_{4-6}$ & -.0033 & $.0063)$ & -.0117 & $(.0103)$ & .0142 & 039) & .019 & $(.0100)$ \\
\hline re Move $\times D E X P M_{7-9}$ & -.0073 & $(.0080)$ & .0047 & $(.0130)$ & .0152 & $(.0049)$ & .0205 & $(.012$ \\
\hline
\end{tabular}

All specifications include the following covariates: dummy variables for experience, age at entry, duration of apprenticeship, abitur, prior experience, transition, and linear time trend.

The specification with occupation variables also includes the mobility variables 'Move' and 'PreMove' interacted with dummy variables for experience when first occupational change occured. 
Table 6: (c) Gender wage gap by work experience controlling for a number of characteristics at entry - training cohort 1990-93

\begin{tabular}{|c|c|c|c|c|c|c|c|c|}
\hline \multirow[t]{2}{*}{ Covariates } & \multicolumn{2}{|c|}{ OLS } & \multicolumn{2}{|c|}{ QR $20 \%$} & \multicolumn{2}{|c|}{ QR $50 \%$} & \multicolumn{2}{|c|}{ QR $80 \%$} \\
\hline & Coeff. & (s.e.) & Coeff. & (s.e.) & Coeff. & (s.e.) & Coeff. & (s.e.) \\
\hline \multicolumn{9}{|c|}{ without occupation/mobility dummies } \\
\hline \multicolumn{9}{|c|}{ Experience in years interacted with male } \\
\hline$D E X P_{0}$ & .1844 & $(.0030)$ & .2089 & $(.0050)$ & .2001 & $(.0019)$ & .1633 & $(.0049)$ \\
\hline$D E X P_{1-3}$ & .1777 & $(.0022)$ & .1941 & $(.0035)$ & .1648 & $(.0013)$ & .1511 & $(.0034)$ \\
\hline$D E X P_{4-5}$ & .1779 & $(.0030)$ & .1924 & $(.0047)$ & .1434 & $(.0018)$ & .1450 & $(.0045)$ \\
\hline \multicolumn{9}{|c|}{ with occupation/mobility dummies } \\
\hline \multicolumn{9}{|c|}{ Experience in years interacted with male } \\
\hline$D E X P_{0}$ & .1134 & $(.0032)$ & .0882 & $(.0051)$ & .1075 & $(.0020)$ & .1307 & $(.0051)$ \\
\hline$D E X P_{1-3}$ & .1122 & $(.0025)$ & .0755 & $(.0038)$ & .0914 & $(.0015)$ & .1176 & $(.0038)$ \\
\hline$D E X P_{4-5}$ & .1185 & $(.0032)$ & .0753 & $(.0047)$ & .0717 & $(.0018)$ & .1089 & $(.0046)$ \\
\hline \multicolumn{9}{|c|}{ Mobility effects interacted with male } \\
\hline Move $\times D E X P M_{0}$ & -.0388 & $(.0165)$ & -.0231 & $(.0337)$ & -.0523 & $(.0129)$ & -.0559 & $(.0333)$ \\
\hline Move $\times D E X P M_{1-3}$ & -.0199 & $(.0087)$ & -.0398 & $(.0136)$ & -.0540 & $(.0052)$ & -.0297 & $(.0135)$ \\
\hline Move $\times D E X P M_{4-5}$ & .0182 & $(.0172)$ & -.0062 & $(.0266)$ & .0123 & $(.0102)$ & -.0092 & $(.0263)$ \\
\hline Pre Move $\times D E X P M_{0}$ & -.0154 & $(.0164)$ & -.0304 & $(.0335)$ & .0004 & $(.0128)$ & .0110 & $(.0331)$ \\
\hline Pre Move $\times D E X P M_{1-3}$ & .0002 & $(.0067)$ & -.0015 & $(.0106)$ & .0212 & $(.0041)$ & .0191 & $(.0105)$ \\
\hline Pre Move $\times D E X P M_{4-5}$ & .0057 & $(.0079)$ & .0166 & $(.0120)$ & .0031 & $(.0046)$ & .0190 & $(.0119)$ \\
\hline \multicolumn{9}{|c|}{$\begin{array}{l}\text { All specifications include the following covariates: dummy variables for experience, } \\
\text { age at entry, duration of apprenticeship, abitur, prior experience, transition, and } \\
\text { linear time trend. }\end{array}$} \\
\hline \multicolumn{9}{|c|}{$\begin{array}{l}\text { 'Move' and 'PreMove' interacted with dummy variables for experience when first } \\
\text { occupational change occured. }\end{array}$} \\
\hline
\end{tabular}

Note for tables 6(a)-(c): The table comprises the coefficient estimates for interactions of dummy variables for experience and mobility with a dummy for males. These are based on OLS/Quantile regression of log wages on a number of covariates. The set of results with occupation/mobility dummies involves in addition 
dummy variables for 2-digit training occupations and gender specific dummy variables for occupational mobility (also interacted with integer years of experience Exper $M$ when the first occupational change occured). The 'move effect' dummy is one after the first occupational change has occured. The 'pre mover' dummy is one for all observations for individuals who report an occupational change during the ten years of their work experience. For all interaction terms of mobility variables with a gender dummy variable, the mobility variable is normalized such that the estimated coefficients for the gender-experience dummy variables reflect the average gender difference for this experience level holding all other covariates constant, see section on methodological aspects in appendix for details. 
Table 7: Gender wage gap by work experience controlling for a number of characteristics at entry if females had male training occupations and male occupational mobility patterns

\begin{tabular}{|c|c|c|c|c|c|c|c|c|}
\hline \multirow[t]{2}{*}{ Covariates } & \multicolumn{2}{|c|}{ OLS } & \multicolumn{2}{|c|}{ QR $20 \%$} & \multicolumn{2}{|c|}{ QR $50 \%$} & \multicolumn{2}{|c|}{ QR $80 \%$} \\
\hline & Coeff. & (s.e.) & Coeff. & (s.e.) & Coeff. & (s.e.) & Coeff. & (s.e.) \\
\hline
\end{tabular}

Cohort 1978-80 without occupation/mobility dummies

Experience in years interacted with male

\begin{tabular}{lllllllll}
$D E X P_{0}$ & .1751 & $(.0037)$ & .1337 & $(.0078)$ & .2063 & $(.0029)$ & .1790 & $(.0074)$ \\
$D E X P_{1-3}$ & .2454 & $(.0024)$ & .3461 & $(.0049)$ & .2237 & $(.0018)$ & .1593 & $(.0047)$ \\
$D E X P_{4-6}$ & .2627 & $(.0026)$ & .3643 & $(.0051)$ & .2165 & $(.0019)$ & .1571 & $(.0048)$ \\
$D E X P_{7-9}$ & .2678 & $(.0027)$ & .3783 & $(.0052)$ & .2104 & $(.0019)$ & .1447 & $(.0050)$ \\
\hline
\end{tabular}

Cohort 1984-86 without occupation/mobility dummies

Experience in years interacted with male

\begin{tabular}{|c|c|c|c|c|c|c|c|c|}
\hline$D E X P_{0}$ & .1462 & $(.0033)$ & .1263 & $(.0068)$ & .1554 & $(.0025)$ & .1235 & $(.0$ \\
\hline$D E X P_{1-3}$ & .2027 & $(.0022)$ & .2638 & $(.0043)$ & .1631 & $(.0016)$ & .1295 & 0040) \\
\hline$D E X P_{4-6}$ & .1652 & $(.0024)$ & .2 & $(.0045)$ & 029 & $(.0016)$ & 99 & $(.0042)$ \\
\hline$D E X P_{7-9}$ & .1279 & $(.0025)$ & .1900 & $(.0047)$ & .0620 & $(.0017)$ & .0493 & $(.0044)$ \\
\hline
\end{tabular}

Cohort 1990-93 without occupation/mobility dummies

Experience in years interacted with male

\begin{tabular}{lllllllll}
$\mathrm{DEXP}$ & .0883 & $(.0030)$ & .1411 & $(.0053)$ & .0789 & $(.0019)$ & .0725 & $(.0050)$ \\
$\mathrm{DEXP} P_{1-3}$ & .0772 & $(.0022)$ & .1266 & $(.0035)$ & .0503 & $(.0013)$ & .0498 & $(.0033)$ \\
$\mathrm{DEXP}$ & .0796 & $(.0029)$ & .1236 & $(.0047)$ & .0324 & $(.0017)$ & .0358 & $(.0044)$ \\
\hline
\end{tabular}

Note: The data for females is simulated based on the technique proposed in Machado and Mata (2005). For this purpose, it is assumed that females have the same characteristics as male but that female coefficients apply. The estimates are obtained analogously to the first set of results for each cohort in table 6 . 
Table 8: Time spent in non-employment during eight years after the start of the first job after apprenticeship (gender differences and wage effects)

\begin{tabular}{|c|c|c|c|}
\hline Specification & (1) & $(2)$ & $(3)$ \\
\hline Covariate & Coeff. & Coeff. & Coeff. \\
\hline \multicolumn{4}{|c|}{ Cohort 1978-80 } \\
\hline \multirow[t]{2}{*}{ Male } & .5094 & .4232 & .4923 \\
\hline & $(.0358)$ & $(.0611)$ & $(.0355)$ \\
\hline \multirow[t]{2}{*}{ Average entry wage for males } & - & - & -1.0011 \\
\hline & & & $(.0091)$ \\
\hline Relative individual entry wage & - & - & -.3029 \\
\hline for males & & & $(.1291)$ \\
\hline \multirow[t]{2}{*}{ Average entry wage for females } & - & - & -.6133 \\
\hline & & & $(.0544)$ \\
\hline Relative individual entry wage & - & - & -1.1496 \\
\hline for females & & & $(.1247)$ \\
\hline \multicolumn{4}{|c|}{ Cohort 1984-86 } \\
\hline \multirow[t]{2}{*}{ Male } & .4680 & .3735 & .4627 \\
\hline & $(.0259)$ & $(.0395)$ & $(.0257)$ \\
\hline \multirow[t]{2}{*}{ Average entry wage for males } & - & - & -.9333 \\
\hline & & & $(.0061)$ \\
\hline Relative individual entry wage & - & - & -.6969 \\
\hline for males & & & $(.1100)$ \\
\hline \multirow[t]{2}{*}{ Average entry wage for females } & - & - & -.5571 \\
\hline & & & $(.0468)$ \\
\hline Relative individual entry wage & - & - & -1.1945 \\
\hline for females & & & $(.0849)$ \\
\hline \multicolumn{4}{|c|}{ Cohort 1990-93 } \\
\hline \multirow[t]{2}{*}{ Male } & .2074 & .1706 & .2059 \\
\hline & $(.0204)$ & $(.0305)$ & $(.0204)$ \\
\hline Average entry wage for males & - & - & -.7352 \\
\hline
\end{tabular}

Continued on next page 


\begin{tabular}{lccc}
\hline $\begin{array}{l}\text { Specification } \\
\text { Covariate }\end{array}$ & $\begin{array}{c}(1) \\
\text { Coeff. }\end{array}$ & $\begin{array}{c}(2) \\
\text { Coeff. }\end{array}$ & $\begin{array}{c}(3) \\
\text { Coeff. }\end{array}$ \\
\hline $\begin{array}{l}\text { Relative individual entry wage } \\
\text { for males }\end{array}$ & - & - & $-.0044)$ \\
Average entry wage for females & & & $(.1093)$ \\
& - & - & -.2713 \\
Relative individual entry wage & - & - & -.6907 \\
for females & & & $(.0816)$ \\
\hline Dummies for training occupation & NO & YES & NO \\
\hline All specifications include the following covariates: age at entry, duration \\
of apprenticeship, abitur, prior experience, transition, and linear time \\
trend.
\end{tabular}

Note: The table comprises the coefficient estimates for the gender variables in an OLS regression of the years spent not working during the first eight years after the end of the apprenticeship. Heteroscedasticity-consistent standard errors are reported in parentheses. For all interaction terms of wage variables with gender dummies, the wage variable is normalized such that the estimated coefficients for the gender-experience dummy variables reflect the average gender difference for this experience level holding all other covariates constant, see section on methodological aspects in appendix for details. 